\title{
MEASUREMENTS TO DETERMINE A RADIATION STANDARD OF THERMAL COMFORT
}

\author{
VANEK, J[osef] \& NESTOROVIC, T[omas]
}

\begin{abstract}
This paper concerns development towards a method for measuring values of radiant norm around humans' head. This norm is important for radiant heating and thermal comfort in the sense of avoiding headaches and overheating as a result of a long-term heat exposure

Key words: low-temperature panels, thermal comfort, radiation efficiency, loss of flow, specific radiant flux
\end{abstract}

\section{INTRODUCTION}

Thermal comfort is important to many work-related factors (air temperature/movement/velocity, relative humidity, floor surface temperature, etc.) (Fountain, 1995). These factors affect a distraction level of workers and in turn affect their performance and productivity of their work. Also, thermal discomfort, especially in the head area has been known to lead to health symptoms. Combining high temperature with high relative humidity serves to reduce thermal comfort and indoor air quality. The occurrence of symptoms increases much more with raised indoor temperatures in winter than in summer due to a larger difference created between indoor and outdoor temperatures.

Finally, let us note that currently there does not exist any precisely provided standard or recommendation that would affect the environmental conditions in general. The only well known limitations widely accepted are the $130 \mathrm{~W} / \mathrm{m}^{2}$ and $250 \mathrm{~W} / \mathrm{m}^{2}$ norms which relate to the minimum and maximum specific heat capacity definition, respectively.

\section{DETERMINING THE RADIANT PANEL EFFICIENCY}

We used a electric low-temperature radiant panel with energy input (EIR) $300 \mathrm{~W}$ and active side maximum surface temperature $100{ }^{\circ} \mathrm{C}$ which is a common type for office rooms temperature regulation. Recall that we aim to determine healthy temperature level to prevent people getting overheated. Our tool are the two mentioned norms $\left(130\right.$ and $\left.250 \mathrm{~W} / \mathrm{m}^{2}\right)$ which we compare with the particular panel specific heat capacity. Let us note that this paper presents merely experimental results and any detailed human-related experiments are a matter of future work (see the proposed questionary below).

\subsection{Determining the Radiant Panel Efficiency}

Before moving to the specific heat capacity determination, let us compare the panel with other radiant panels in the low temperature panels class. In this section, we will consider two comparison parameters - total heat losses and efficiency.

To compute the heat stream losses $P$, we used the Newton flow law which states that emitted energy is directly depended on the surface of a heat emitting object and the difference of this object temperature to an ambient temperature:

$$
P=\alpha \cdot\left(\tau-\tau_{0}\right) * S \quad\left[\mathrm{~K} * \mathrm{~W} / \mathrm{m}^{2}\right],
$$

where $\alpha$ is an empirical C-value coefficient, $S$ is the object surface, and $\tau$ and $\tau_{0}$ are the object average and ambient temperatures, respectively. In this equation, $\alpha$ and $\tau$ are the unknown variables. One of approaches to determine them is conducting measurements on all sides of the heat emitting object. Thus having a radiant panel, we can measure partial temperatures on all its sides and combine them into a single result. Our measurements account for the radiant panel's active and inactive sides, and all four vertical sides. Let us denote these temperatures $\tau_{\mathrm{i}}$ with $i$ ranging from 1 to 6 (Table 1). As for the $\mathrm{C}$-value coefficient $\alpha$, we already mentioned that it is an empirical value usually computed according to the following formula (Hottel \& Sarofim, 1967):

$$
\alpha_{\mathrm{i}}=K_{\mathrm{i}} \cdot \operatorname{pow}\left(\tau_{\mathrm{i}}-\tau_{0}, 0.25\right)
$$

in which $K_{\mathrm{i}}$ is a particular empirical weight coefficient which acts here as an influence factor to precise the resulting $\alpha$ value (Table 1). Thus, we put six C-value coefficients $\alpha_{\{1 \ldots 6\}}$ back into the Newton flow law formula to obtain partial heating losses $P_{\mathrm{i}}$ on each particular side of the panel:

$$
P_{\mathrm{i}}=\alpha_{\mathrm{i}} \cdot\left(\tau_{\mathrm{i}}-\tau_{0}\right) \cdot S_{\mathrm{i}} \quad[\mathrm{K} * \mathrm{~W} / \mathrm{m} 2]
$$

Adding these partial yields the total heating loss $P=\sum_{(\mathrm{i})} P_{\mathrm{i}}$. Finally, we can determine the radiant panel efficiency $\mu$ by putting the total heating loss $\mathrm{P}$ value into the common efficiency computation equation

$$
\mu=100 \cdot(\mathrm{EIR}-P) / \mathrm{EIR} \quad[\%]
$$

which results in efficiency of $50.6 \%$. Let us note that in comparison with other radiant panels within the low temperature panels class, this panel has a relatively higher efficiency (it commonly is scattered around $40 \%$ ). There are two possible causes of this- first, its inactive side is shielded preventing the produced heat to get lost, and second, the panel is dark brown coloured which predetermines it for a higher efficiency due to lower heating loss.

\begin{tabular}{|c|c|c|c|c|c|c|c|}
\hline$i$ & $K_{\mathrm{i}}[-]$ & Sides of panel & $S_{\mathrm{i}}\left[\mathrm{m}^{2}\right]$ & $\alpha_{\mathrm{i}}$ & $P_{\mathrm{i}}$ & $\tau_{\mathrm{i}}\left[{ }^{\circ} \mathrm{C}\right]$ & $\tau_{\mathrm{i}}[\mathrm{K}]$ \\
\hline 1 & 2,56 & active side & 0,33 & 3,4 & 82,4 & 96,7 & 369,8 \\
\hline 2 & 2,15 & inactive side & 0,33 & 4,4 & 25 & 40,2 & 313,3 \\
\hline 3 & 1,15 & left side & 0,04 & 5,7 & 4,7 & 47 & 320,1 \\
\hline 4 & 1,15 & right side & 0,04 & 6 & 6,3 & 53,2 & 326,4 \\
\hline 5 & 1,15 & front side & 0,04 & 5,8 & 5,5 & 50,00 & 323,2 \\
\hline 6 & 1,15 & rear side & 0,04 & 6 & 6,5 & 54,1 & 327,2 \\
\hline
\end{tabular}

Tab. 1. Average temperature at each panel side in [ $\mathrm{C}]$ and $[\mathrm{K}]$

\subsection{Determining Radiant Panel Specific Heat Capacity}

With knowing the radiant panel basic parameters, we can proceed to determine the panel's specific heat capacity and compare it with the 130 and $250 \mathrm{~W} / \mathrm{m}^{2}$ norms.

During the experiments, we conducted three measurements in different distances from the radiant panel. More particularly, a square radiant panel of a size $57 \mathrm{~cm}$ was positioned 2.60, 1.60 , and 1.00 meters away from a 2.70 meter square surface. The mutual position of these two surfaces can be seen in Fig.1. The evaluation of our measurements can be done from two points of view - a formal and informal ones. 


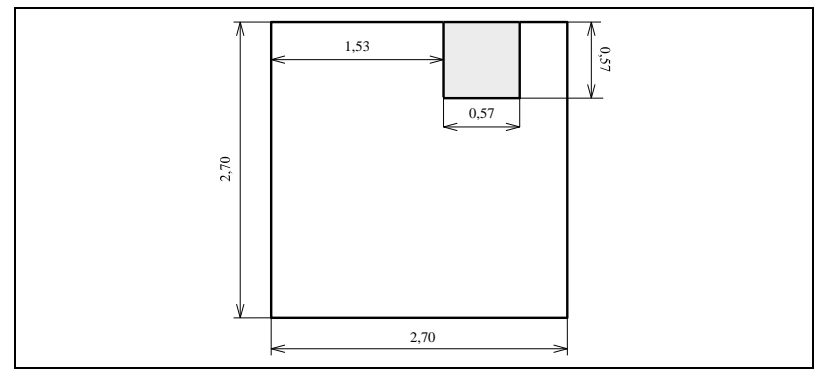

Fig. 1. Radiant panel and measured surface mutual position

The formal evaluation accounts for computing the specific heat capacity $Q$ as announced above and comparing it with the 130 and $250 \mathrm{~W} / \mathrm{m}^{2}$ norms. The formula we used can be broken down into three parts: environmental constants $E$, temperature gain $\Delta \tau$, and radiant panel influence on the measured surface $I$. Thus, $Q=E \cdot \Delta \tau \cdot I$. The environmental constants cover emissivity $\varepsilon_{0}$ and $\varepsilon$ (of the panel and measured surface, respectively), and Stefan-Boltzman constant $c_{0}$. The temperature gain informs how much heat has been absorbed at particular point of the measured surface, thus $\Delta \tau=\tau_{0}^{4}-\tau^{4}$. Finally, the influence can be thought of as a kind of weight function which prioritizes measured surface points located directly under the radiant panel while putting less stress on points further from it. Hence, the final formula is as follows (Moran et al., 2003):

where $\tau_{0}$ and $\tau$ are the the panel and measured surface average temperatures, respectively, $\beta_{0}$ and $\beta$ are angles from the panel or measured surface normal to the join of points $d S_{0}$ and $d S$, respectively, and $r$ is the distance between the points $d S_{0}$ and $d S$. However, we need to adjust this general form to fit our discrete measurements:

Note that in this case we approach the integral by merely a distance and angle between centroids of the radiant panel and the measured surface particular patch $S_{\mathrm{i}}$ (each of which is always parallel with the panel implying the square cosine).

The respective heat capacities are 61.2, 128.5, 180.3 for the $2.60,1.60$, and $1.00 \mathrm{~m}$ distance. As it can be seen, only the first two comply with the $130 \mathrm{~W} / \mathrm{m}^{2}$ norm and all of them comply with the $250 \mathrm{~W} / \mathrm{m}^{2}$ norm. According to this observation, we can claim that a radiant panel of this type and energy should be positioned approximately between 1.60 and 2.60 meters above human heads (obviously depending on the season).

However, formal evaluation is just one (objective) side of human thermal comfort. The another one are particular person's feelings. Although we have not conducted these subjective evaluations yet, we propose the following scenario of experiments and surveys to precise the objective formal evaluation.

(1) Before-testing phase questionnaire. (a) Question: How are you feeling? (Please check all meeting conditions.) Offered answers: suffering from headache; feeling ill; feeling alright; feeling a bit dizzy; feeling a bit unconcentrated, feeling nervous. (b) Question: How do you reckon the current temperature in this room? Offered answers: rather cold, pleasant, rather hot, very hot. (c) Measuring the subject's initial temperature and inflation pressure.

(2) Testing phase begin. Setting the room temperature to a particular random value to fit in the specific heat capacity range (see above).

(3) Perception experiment. In this test, the subject is exposed to a screen with different symbols appearing on it (numbers and/or letters), and the goal is to measure the latency between a symbol appearance and corresponding keyboard symbol press under the thermal conditions set in the previous step.

(4) Concentration experiment. In this test, the subject is given a paper printed with symbols which differentiate from each other merely in details (e.g. the letters $\mathrm{O}$ and $\mathrm{Q}$ differentiate merely in a small tail under them), and the subject's goal is to find and mark in this paper only a predefined kind of a symbol and leave all others unchecked.

(5) Testing phase end.

(6) After-testing phase questionnaire. Questions (a)-(c) from Step 1 repeated. (d) Question: Can you imagine working or living in a room/flat with temperature like this? Offered answers: no; rather not; do not know; rather yes; yes.

Let us note that the perception and concentration tests (Steps 3 and 4) are adopted from medical studies on EEG signals (Coufal \& Mojžíš, 2008; Mojžíš \& Coufal, 2009) where they act as a common way of testing people's reflections. We involved them into our scenario as we want to raise cognitive load in people's minds in order to simulate work in a office/ flat. The before-testing phase (Step 1) is present to calibrate these tests initial conditions (each person has a different opinion to the thermal comfort term). Finally, the after-testing phase survey (Step 6) and the results of the tests (number of seconds before pressing a key in Step 3 or mischecked symbols in Step 4) are thermal comfort quality indirect measures to give us a suggestion of changes to make before running a next iteration of the (subjective) evaluation. Programming implementation of the two interactive tests (Steps 3 and 4) is our current work in progress.

\section{CONCLUSION}

This paper presented our approach to measuring a specific heat capacity of a radiant panel in order to roughly determine a temperature range which is in coherence with current temperature comfort norms. Furthermore, we showed our scenario proposal for narrowing this range to fit thermal needs of a particular group of people based on their survey responses and two cognitive tasks.

\section{ACKNOWLEDGEMENTS}

This paper was supported by grants SGS-2010-028 (Advanced Computer and Information Systems) and FF1500/2011/G1.

\section{REFERENCES}

Coufal, J. \& Mojžíšs, M. (2008). Simulation Framework for ERP Experiments, Proceedings of 9th International PhD Workshop on Systems and Control, Izola, Slovenia, Gašperin, Pregelj (Eds.), pp. 39-42

Fountain, M. (1995). An Empirical Model for Predictin Air Movement Preferred in Warm Office Environments, Proceedings of Standards for Thermal Comfort, London, ISBN 0419204202, Nicol, Humpreys, Sykes, Road (Eds.), pp. $40-43$

Hottel, H.C. \& Sarofim, A.F. (1967). Radiative Transfer. McGraw-Hill Company, New York

Mojžíšs, M \& Coufal, J. (2009). Design experimentů pro EEG/ERP (Designing EEG/ERP Experiments), Proceedings of Kognice a umélý život (Cognition and Artificial Life), Czech Republic, ISBN 9788072485161, pp. 213-218

Moran, M.J., Shapiro, H.N., Munson, B.R., \& DeWitt D.P. (2003). Introduction to thermal systems engineering, John Wiley \& Sons, New York 